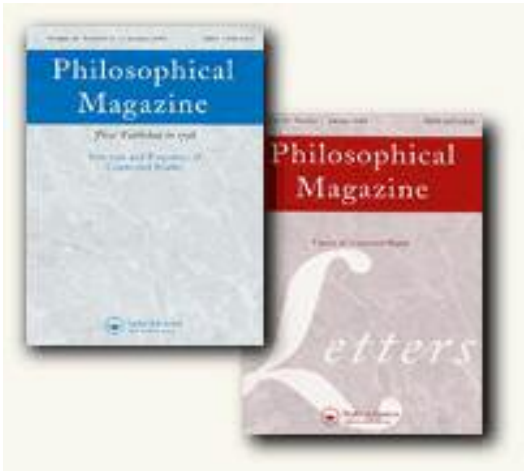

\title{
Experimental and numerical investigation of creasing in corrugated paperboard
}

\begin{tabular}{|r|l|}
\hline Journal: & Philosophical Magazine \& Philosophical Magazine Letters \\
\hline Journal Selection: & Philosophical Magazine \\
\hline Author: & 23-Jun-2008 \\
\hline Complete List of Authors: & $\begin{array}{l}\text { Thakkar, Bhairav; Eindhoven University of Technology, Department } \\
\text { of Mechanical Engineering } \\
\text { Gooren, Luc; Eindhoven University of Technology, Department of } \\
\text { Mechanical Engineering } \\
\text { Peerlings, Ron; Eindhoven University of Technology, Department of } \\
\text { Mechanical Engineering } \\
\text { Geers, Marc; Eindhoven University of Technology, Mechanical } \\
\text { Engineering }\end{array}$ \\
\hline Keywords: & $\begin{array}{l}\text { anisotropy, cracking, damage, deformation mechanisms, finite- } \\
\text { element modelling, materials characterisation, mechanics of } \\
\text { materials, paper }\end{array}$ \\
\hline Keywords (user supplied): & corrugated paperboard, creasing \\
\hline & \\
\hline $\begin{array}{l}\text { Note: The following files were submitted by the author for peer review, but cannot be converted } \\
\text { to PDF. You must view these files (e.g. movies) online. }\end{array}$ \\
\hline $\begin{array}{l}\text { thakkar_pm_ias07_revised.tex } \\
\text { thakkar_pm_ias07_revised.bib }\end{array}$ \\
\hline
\end{tabular}




\section{S. ScholarONE"}


Philosophical Magazine

Vol. 00, No. 00, June 18, 2008 2008, 1-10

\title{
RESEARCH ARTICLE
}

\section{Experimental and numerical investigation of creasing in corrugated paperboard}

\author{
B K Thakkar, L G J Gooren, R H J Peerlings* and M G D Geers \\ Department of Mechanical Engineering, Eindhoven University of Technology, \\ PO Box 513, 5600 MB Eindhoven, The Netherlands \\ (v4.0 released January 2008)
}

\begin{abstract}
Creasing is a process which indents a section of corrugated board along fold lines to facilitate a neat fold. Most common failure site in a box made out of corrugated board is at the folds, where the stiffness is reduced by the creasing operation. Crease depth is an important parameter to be controlled. If the crease is too shallow, the section will crack during folding due to excessive strain on the outer liner. On the other hand, if the crease is too deep, the board may crack during the creasing operation itself or it may fail during handling due to excessive reduction in local strength along the fold line.

A review of the literature reveals that only a limited amount of research has been carried out on experimental creasing of corrugated boards and comparison with numerical analyses. However, modelling of paper for corrugated board has been successfully done using Hill's plasticity model. In this work, experimental investigations on creasing of corrugated paperboard are carried out. These are complemented by finite element simulations of the creasing process. The simulations are found to be in good agreement with the experimental results. The findings of the work done are helpful in understanding the mechanics of creasing more clearly and in arriving at an appropriate crease depth in order to reduce cracking of corrugated board during the creasing process.
\end{abstract}

Keywords: corrugated paperboard; creasing; paper characterisation; cracking

\section{Introduction}

Packaging boxes are usually made from corrugated paperboard. Such a box is shown at different spatial scales in Figure 1. Corrugated board consists of two nominally flat sheets of paper, called liners, and a corrugated sheet, called flute, in between. The corrugated architecture imparts bending stiffness to the board.
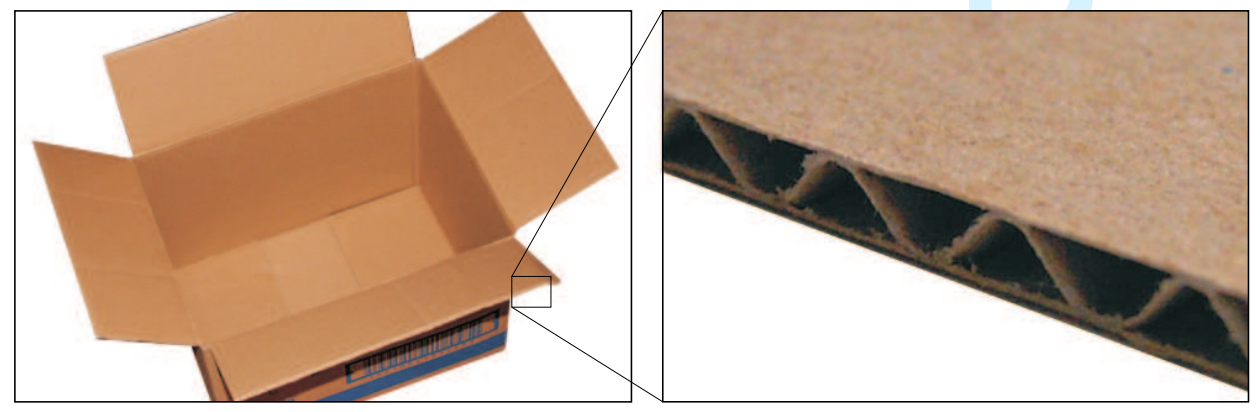

Figure 1. A corrugated board box at different scales

\footnotetext{
*Corresponding author. Email: R.H.J.Peerlings@tue.nl
}

ISSN: $1478-6435$ print/ISSN 1478-6443 online

(C) 2008 Taylor \& Francis

DOI: $10.1080 / 1478643 Y Y x x x x x x x x$

http://www.informaworld.com 
The corrugated board is folded to make boxes of the required shape and size. To obtain neat folds, it is required to make fold lines (creases) on the board. These creases reduce the stiffness of the board. A board with creases, cuts and cracks is shown in Figure 2. The creasing operation is performed by indenting a creaser knife on the corrugated board. If the crease is too deep, excessive strain is observed on the top liner. If the strain is higher than the rupture strain of the constituent paper, cracking of the top liner results. If the crease is too shallow, the outer liner will crack during folding due to excessive strain. It is therefore important to clearly understand the behaviour of corrugated paperboard during the creasing process and during the subsequent folding. The cracking of corrugated boards is more pronounced during dry and cold conditions. Hence, in such conditions, it is important that a balanced creasing depth be determined.

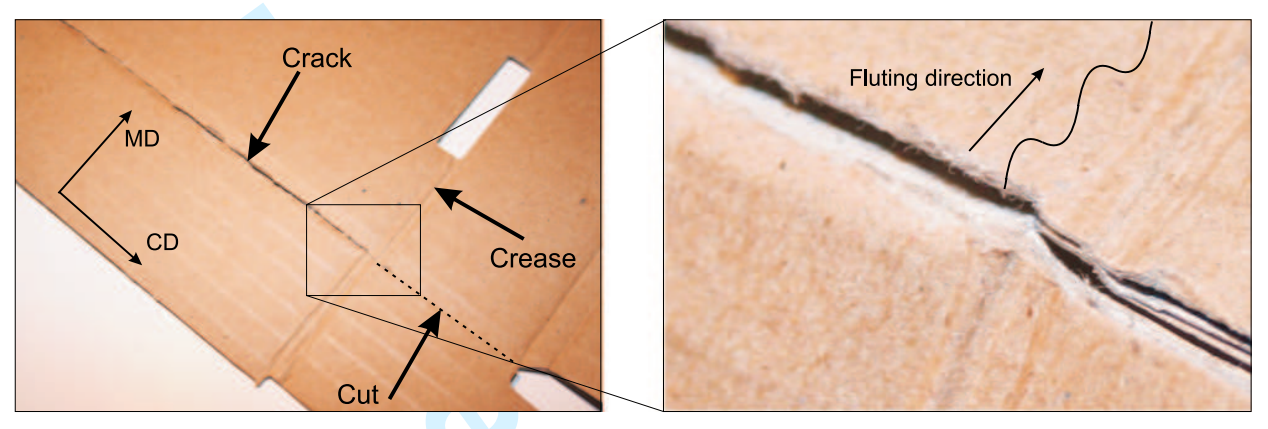

Figure 2. A piece of corrugated board with creases and cuts; cracking can be observed in the image on the right

In order to study the mechanics governing the creasing of corrugated paperboard, creasing experiments have been conducted on corrugated board samples. Experiments have also been conducted on the constituent paper to obtain its mechanical properties for subsequent use in numerical simulations. Finite element analyses have been performed to compare with the experimental observations. The numerical simulations of creasing compare well with the experimental observations.

The structure of this contribution is as follows. First a brief review is given of the relevant literature. Experiments are then described which have been used to characterise the individual papers which constitute the board, followed by creasing experiments. The finite element modelling used to analyse the creasing experiments is detailed subsequently. Results of the creasing experiments and simulations are presented together in Section 6, before the paper closes with a brief summary of conclusions.

\section{Literature}

The literature on the mechanics of paper and paperboard has so far mainly concentrated on characterising the mechanical response of paper and solid paperboard. Xia et al. [1] proposed a model with orthotropic elastic behaviour and an orthotropic yield surface constructed from sub-surfaces with orthotropic hardening. Stenberg [2] developed a model based on the idea of a bounding surface that grows in size with plastic compression for modelling various processes such as calendaring, cutting and folding. The bounding surface and yield surface are assumed to be parabolic in stress space. Castro and Ostoja-Starzewski [3] developed a constitutive model of paper for in-plane bi-axial tension, considering an elastic-plastic response and orthotropy of the materials. Makela and Ostlund [4] described an elasticplastic orthotropic constitutive model suitable for paper in which the anisotropic 
behaviour is introduced by a transformation tensor. Isaksson et al. [5] applied a non-local gradient damage model to perform failure studies on isotropic paper. Likewise, Isaksson and Hagglund [6] performed damage studies on multi-ply fibre boards, wherein each layer was modelled as homogeneous and isotropic. A gradient enhanced non-local continuum damage theory based on that developed by Peerlings et al. [7] was adopted. Isaksson et al. [8] used gradient enhanced damage for the description of failure in paperboard. Further, they applied Hill's yield criterion to introduce anisotropic plasticity.

Studies of the overall response of corrugated board have also been performed. Nordstrand and Carlsson [9] determined effective transverse shear moduli along the principal material directions of corrugated board using the ASTM block shear test and three point bend test. Biancolini [10] developed a method to estimate the elastic stiffness of corrugated board panels. Urbanik [11] developed a localized buckling theory to predict the buckling behaviour of corrugations. The formulation is based on the theory of elastic plates. Buckling curves are obtained in machine direction and cross direction. Gilchrist et al. [12] performed nonlinear finite element analyses of corrugated boards. Uniaxial, biaxial and in-plane shear tests were done to obtain the model constants. An elastic-plastic material model was applied, in combination with shell elements. For the prediction of yielding, isotropic hardening and Hill's yield criterion were adopted. Nyman [13] studied local buckling of corrugated board facings under in-plane loading. An approximate analytical model was proposed for local buckling that enables a risk assessment of buckling without extensive numerical analysis.

Creasing and folding of paper have been studied by Barbier et al. [14, 15] and by Murayama et al. [16]. For corrugated board, Nordstrand [17] used a panel testing rig to perform buckling analyses with initial imperfections due to creases. The Tsai-Wu criterion was employed to predict the failure load, which was in close agreement with that observed experimentally. An experimental study on crack propagation during converting has been reported by Cavlin and Edholm [18]. This study revealed a strong correlation of the amount of crack propagation with the compressive strength of the flute and the breaking strain of the liner.

A detailed experimental-numerical analysis of the mechanics relevant to creasing of corrugated board appears to be lacking - a gap which the present contribution aims to fill.

\section{Paper Characterisation}

In order to model corrugated paperboard for finite element analysis, the mechanical properties of the constituent papers are essential. These properties have been determined by performing experiments on samples made out of the papers. Tensile and compressive tests were conducted on the liner and flute materials in machine direction (MD) and cross direction (CD). During creasing, the top liner is under tension, the bottom liner could be under tension or compression and the flute is predominantly under compression. Additional tensile tests under $45^{\circ}$ allow one to also determine the shear properties [19].

It is extremely difficult to measure the out-of-plane properties. Hence, the outof-plane properties of top liner and flute have been adopted as those for the CD direction. This is a relatively crude assumption, as the true out-of-plane stiffness of paper may be up to two orders of magnitude lower than its in-plane stiffness - see e.g. [2]. However, as we will show below, the board's mechanical response to creasing is governed predominantly by the in-plane properties of the paper (in $M D)$ and variations of the out-of-plane stiffness have comparatively little influence 
on this response.

The tensile tests have been carried out under the same conditions as the subsequent creasing test and at comparable loading rates. The tensile test samples were cut from a large sheet using a cutting punch. The shape and dimensions of the test samples are shown in Figure 3. The dimensions have been chosen such that they are comparable to those of the creasing samples and fit in the micro-tensile stage used also for creasing. The average thickness of the paper was determined to be $180 \mu \mathrm{m}$ by optical microscopy. The test gauge length was maintained to $10 \mathrm{~mm}$.

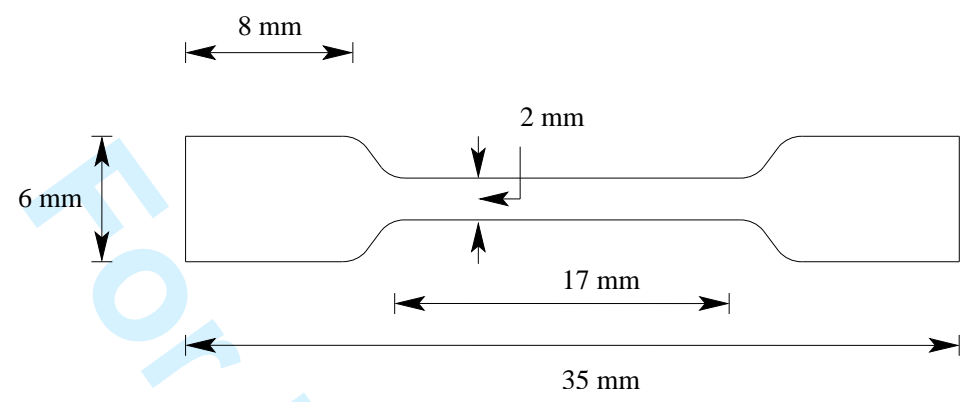

Figure 3. Tensile test specimen geometry used to characterise the constituent papers

A series of compression tests were also conducted in MD and CD directions. The gauge lengths for the compression tests were maintained to $4 \mathrm{~mm}$. Since this is a relatively large gauge length, the elasticity modulus obtained can be unreliable as the axial compression may give rise to buckling. Hence, to confirm the obtained elasticity modulus, comparisons were made with Euler's buckling force, which is given by:

$$
P_{\mathrm{cr}}=\frac{\pi^{2} E I}{L_{\mathrm{e}}^{2}}
$$

The paper fixities in the test were rigid as compared to the overall stiffness of the paper sample. Under fixed end conditions, the effective length equals $L_{\mathrm{e}}=$ $L / 2$. The critical load can be obtained from the experiment as the peak load observed during a compression test. The moment of inertia of the sample has been calculated considering uniform properties over the thickness. The value of the elasticity modulus so obtained compares well with the initial slope of the stressstrain curve.

The Young's moduli in machine direction $\left(E_{1}\right)$ and cross direction $\left(E_{2}\right)$ were directly determined by measuring the initial slope of the stress-strain curves. They were obtained as $E_{1}=3950 \mathrm{MPa}$ and $E_{2}=1650 \mathrm{MPa}$ respectively. Digital Image Correlation (DIC) was used to determine the Poisson's ratios. The in-plane Poisson's ratio $\nu_{12}$ was determined as $\nu_{12}=0.65$. With the above known parameters, using elasticity theory, the shear modulus $G_{12}$ was determined from a $45^{\circ}$ test as $G_{12}=760 \mathrm{MPa}$.

A clear yield point is not visible in the paper's stress-strain response. The material nevertheless shows a significant amount of permanent strain upon unloading. This is illustrated in Figure 4, which shows the results of loading-unloading tests in MD and CD. These results have been used to estimate the yield stresses in these two directions as the stress at which unloading first resulted in an appreciable amount of permanent deformation; this resulted in $\sigma_{11 \mathrm{y} 0}=13 \mathrm{MPa}$ and $\sigma_{22 \mathrm{y} 0}=4 \mathrm{MPa}$. Note that a small deviation of the yield stress can be compensated 
in the hardening relation without affecting the total stress-strain response, so the accuracy of the initial yield stresses is not very critical.
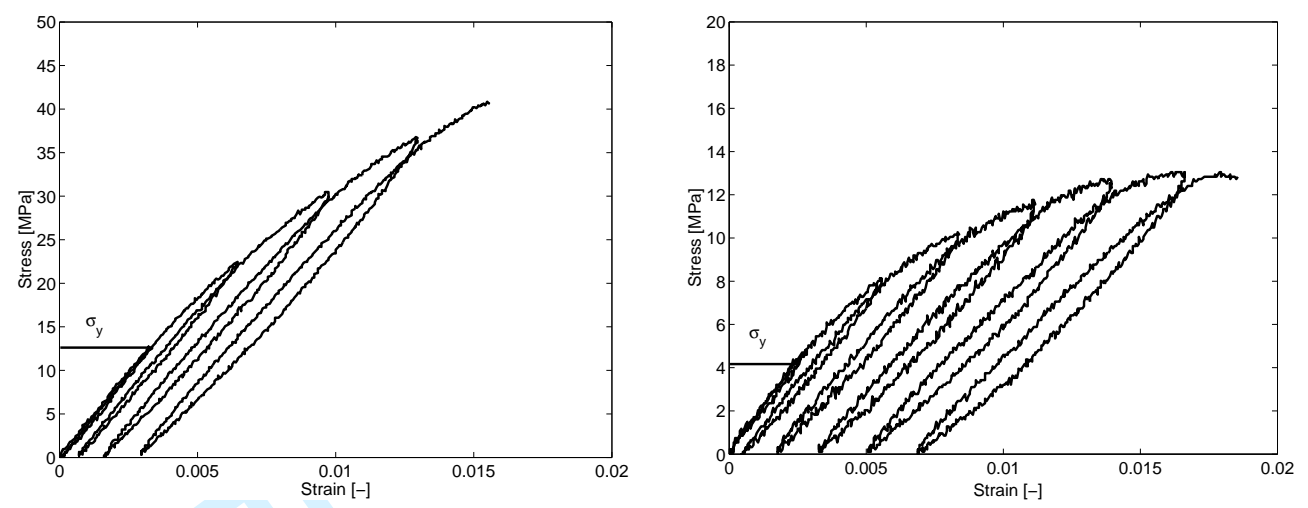

Figure 4. Stress-strain curve illustrating elastoplastic behaviour in MD (left) and CD (right) under loading and unloading

As can be observed in Figure 4, paper exhibits a non-linear hardening behaviour. A power law relation between the yield stress $\sigma_{\mathrm{y}}$ and the effective plastic strain $\bar{\varepsilon}_{\mathrm{p}}$ describes this post-yield behaviour (in MD) quite accurately:

$$
\sigma_{\mathrm{y}}=\sigma_{\mathrm{y} 0}\left(1+A \bar{\varepsilon}_{\mathrm{p}}\right)^{m}
$$

with $A=3900$ and $m=0.37$. Isotropic hardening is used, i.e. the yield surface scales with the yield stress given by Equation (2). To simulate the most critical case, Relation (2) was fitted to the stress-strain curve with the lowest failure strength. The resulting in-plane elasto-plastic response fits that of the tensile tests in $M D$, $C D$ and $45^{\circ}$ quite well (not shown here).

\section{Creasing Test}

Creasing experiments have been conducted on samples of corrugated board. For this purpose a set of creasing tools was developed whose geometries are representative for industrial creasing. The tools were inserted in a micro-tensile stage, thus allowing one to measure the displacement of the creasing knife and the force acting on it, while simultaneously observing the deformation of the board by optical or electron-microscopy. The experimental setup including creaser is shown in Figure 5.

Creasing tests have been carried out on peak and valley positions as indicated in Figure 6. Cracking of the top liner is more likely when creasing is done on the valley position, since in this position the top liner undergoes the largest amount of tensile strain for a given displacement of the creaser. In the peak position, the flute wave below the creaser gets crushed and the portion of the liner which accommodates the required elongation is effectively doubled, hence reducing the strain in it compared with the valley case.

\section{Numerical Simulations}

Numerical simulations have been performed using MSC.Marc. The corrugated board was modelled using two-dimensional bi-linear plane strain elements with additional assumed strain modes and a constant dilatation. The finite element mesh 
June 18,2008
Page 7 of 24

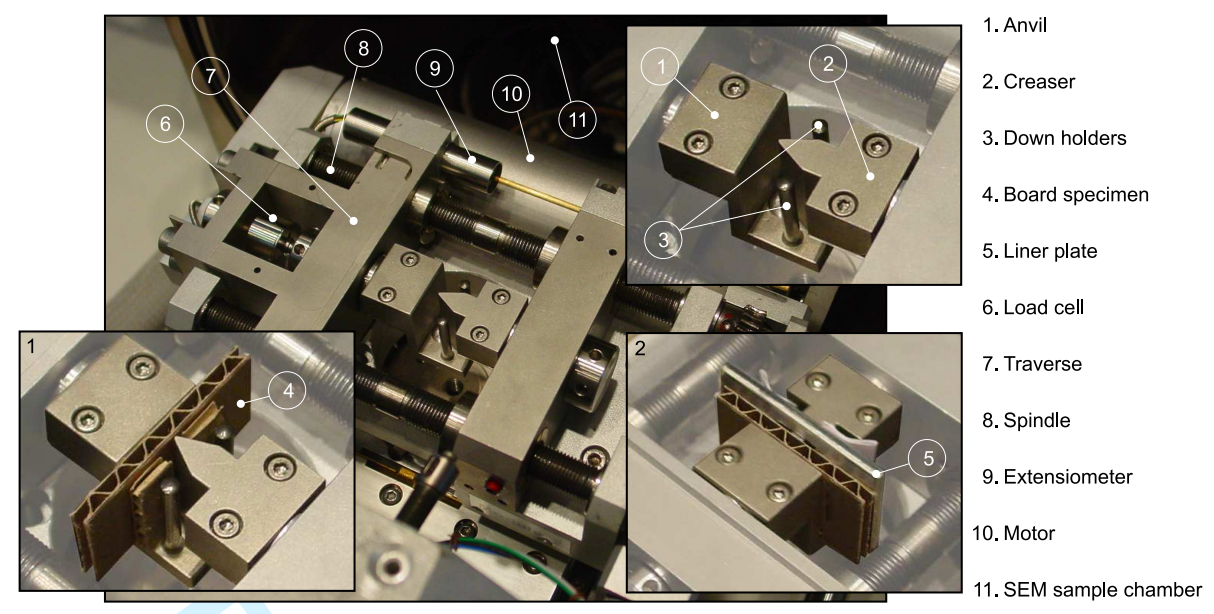

Figure 5. The experimental setup used in the creasing experiments; it is based on a micro-tensile stage, for which a creasing tool has been designed

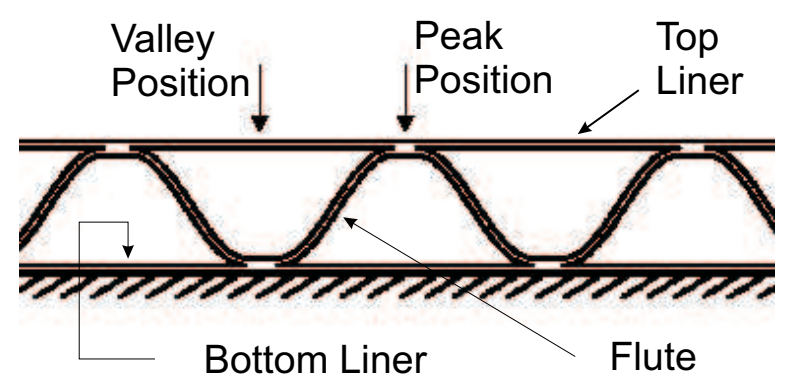

Figure 6. Horizontal positions of the creasing knife with respect to the flute at which tests have been done

is shown in Figure 7. It uses six elements across the thickness of each paper ply. The complete mesh consists of 11,300 nodes and 9,840 elements. Further refining it did not result in significant changes in the computed response.

The corrugated board is restrained by an anvil contact body and an indenter contact body, which are both modelled as rigid. Excessive lifting of the specimen is prevented using rigid down-holder contact bodies towards the edges of the board. Self-contact of the board is included by defining the flute and liners as individual, deformable contact bodies.

The material modelling adopted for the liners and flute is based on the mechanical properties as obtained experimentally in Section 3. Given the degree of anisotropy and inelastic deformation observed, an orthotropic finite-strain elasto-plasticity formulation has been adopted. As a yield criterion, the Hill'48 criterion has been used. Even though this criterion was developed for sheet metal, it describes the inelastic straining of paper with reasonable accuracy. The general yield criterion can be written as:

$$
\begin{aligned}
f=F\left(\sigma_{22}-\sigma_{33}\right)^{2}+G\left(\sigma_{33}-\sigma_{11}\right)^{2}+ & H\left(\sigma_{11}-\sigma_{22}\right)^{2} \\
& +2 L \sigma_{23}^{2}+2 M \sigma_{31}^{2}+2 N \sigma_{12}^{2}-1 \leq 0
\end{aligned}
$$

where the subscripts ${ }_{i i}$ indicate the normal stresses and ${ }_{i j}$ indicate the shear stresses in the principal directions of orthotropy. The coefficients $F, G, H, L, M$ and $N$ characterise the anisotropy of the yield surface; they can be related to the yield 


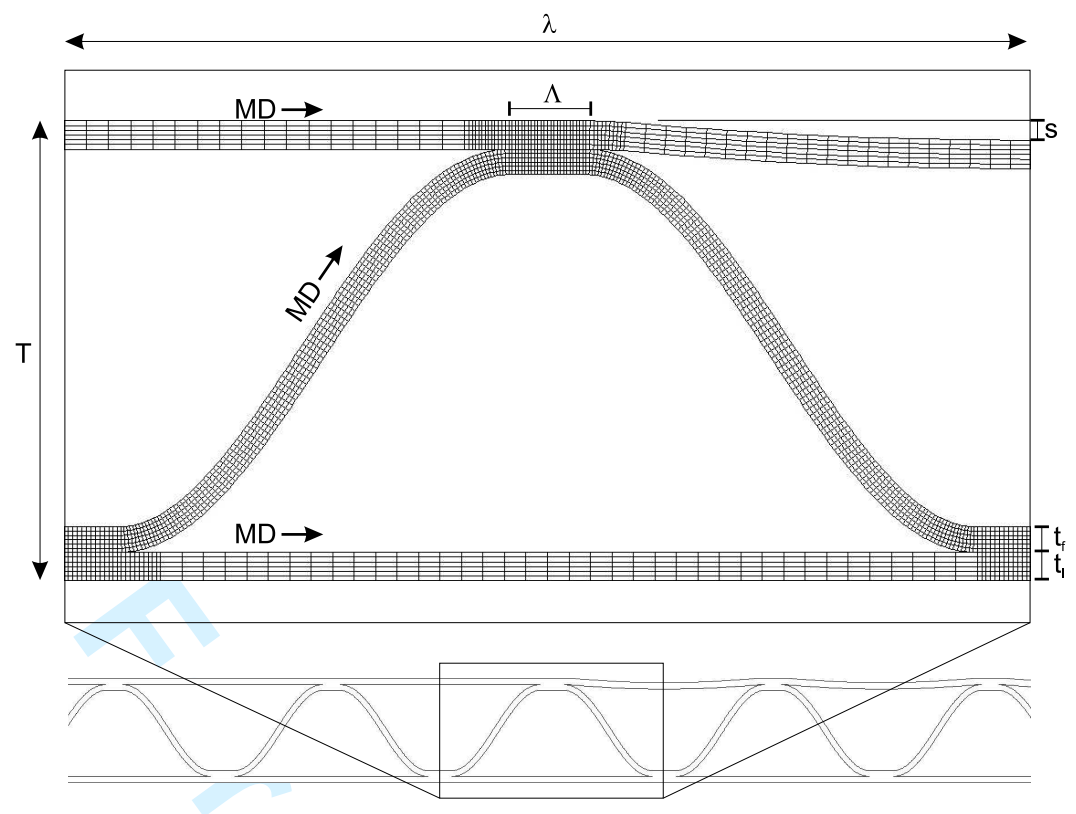

Figure 7. Finite element model of the creasing test on corrugated board

stresses in the orthotropy directions as

$$
\begin{array}{ll}
2 F=\frac{1}{\sigma_{22 y}^{2}}+\frac{1}{\sigma_{33 y}^{2}}-\frac{1}{\sigma_{11 y}^{2}} & 2 L=\frac{1}{\sigma_{23 y}^{2}} \\
2 G=\frac{1}{\sigma_{11 y}^{2}}+\frac{1}{\sigma_{33 y}^{2}}-\frac{1}{\sigma_{22 y}^{2}} & 2 M=\frac{1}{\sigma_{31 y}^{2}} \\
2 H=\frac{1}{\sigma_{11 y}^{2}}+\frac{1}{\sigma_{22 y}^{2}}-\frac{1}{\sigma_{33 y}^{2}} & 2 N=\frac{1}{\sigma_{12 y}^{2}}
\end{array}
$$

The above yield criterion was combined with the standard finite-strain elastoplasticity formulation of MSC.Marc, which is based on an additive split of the deformation rate into an elastic and a plastic part. Hypo-elasticity, based on Jaumann's objective stress rate, is used to describe the elastic response. The plastic response is governed by normality with respect to the yield surface given by (3) and the isotropic hardening law (2). The incremental-iterative solution procedure follows an updated Lagrange approach.

\section{Results}

A comparison of the simulated load-displacement curve with the band of experimental observations is shown in Figure 8 for the valley position. Both results show a number of marked peaks which are associated with buckling of the flute. The board experiences an almost sudden loss in stiffness due to buckling of one wave of the flute. However, on further creasing, the nearby flute waves also get stressed and contribute to a renewed increase of the creasing force. The force levels predicted by the finite element simulation match well with the experimental observations for moderate creasing depths. For larger depths, i.e. beyond the first buckling, the predicted force deviates somewhat from the experimental band.

Figure 9 shows a comparison of the deformed shape as observed in micrographs taken during the experiment and as predicted by the simulation. It can be observed 


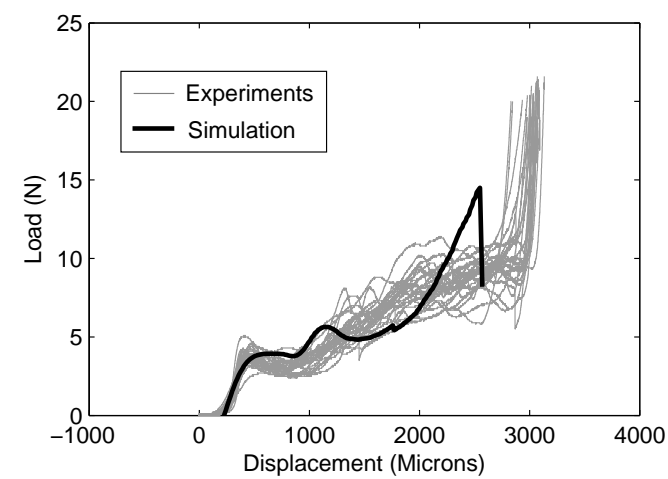

Figure 8. Comparison of the creasing simulation with experimental load-displacement curves

that the deformed shapes compare well throughout the creasing process. As in experiments, after the simulation is over, buckled flutes are observed as shown in Figure 10.

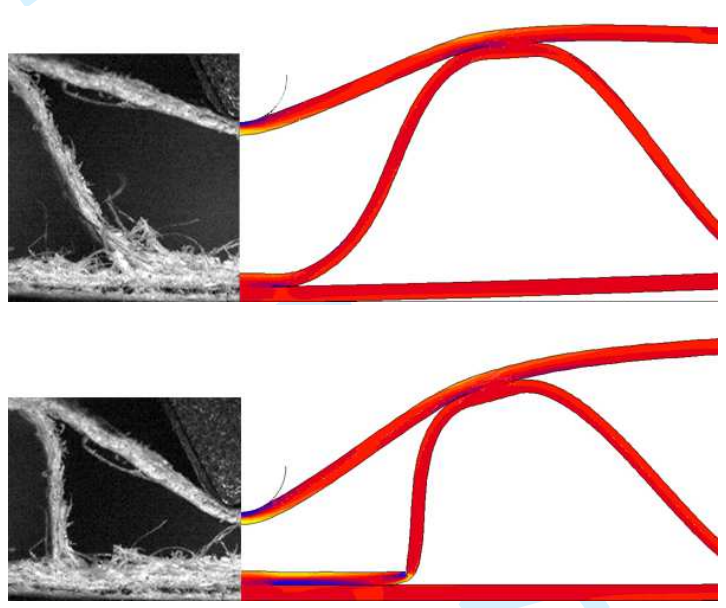

Figure 9. Comparison of the simulated deformation pattern with that experimentally observed

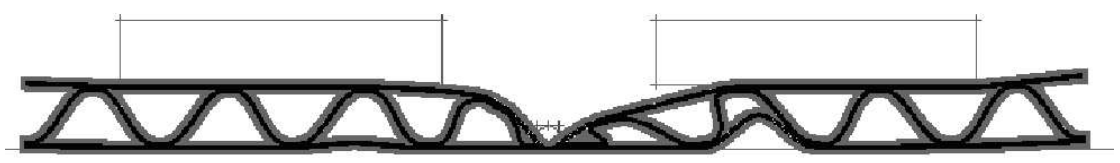

Figure 10. Predicted shape of the corrugated board specimen at the end of the creasing test

From the simulations, it can be observed that during creasing the flute is under compression and bottom liner is under tension. In case of creasing on the peak position, the top liner is under much less tension. But during creasing on the valley position, the top liner is initially under bending and as the crease depth increases it experiences an increasing amount of tension. Thus, it can be said that the tensile properties of top liner and compressive properties of the flute are of most importance during creasing. Note that this observation corresponds well with conclusions drawn from experiments by Cavlin and Edholm [18].

The observation that the in-plane (MD) properties of the paper are of most importance during creasing explains the accurate prediction of the load levels reached: 
the constitutive relations used were fitted mostly to in-plane (MD) experiments and capture the response observed in them quite accurately. This suggests that whereas more detailed and advanced constitutive models for paper are available, see e.g. $[1,2]$, their use may be of limited added value in the comparatively simple stress states which govern creasing of corrugated paperboard. An exception may be constitutive models which aim to also predict the onset of failure of the paper, see e.g. [5] - this is a feature which our present modelling clearly does not include.

In our simulations, the highest tensile stresses are observed underneath the creaser, indicating a potential site for crack initiation and propagation. Indeed, in the experiments there is substantial degradation under the creaser after the completion of the creasing process. Even though there were no macroscopically visible cracks, micrographs of the region immediately below the creaser reveal a considerable amount of degradation. The micrograph on the left in Figure 11 shows the degraded paper under the creaser along with the less degraded portion. Observing the sample laterally, a number of fibres can be observed to have flung out of the plane of paper in the micrograph on the right in Figure 11.
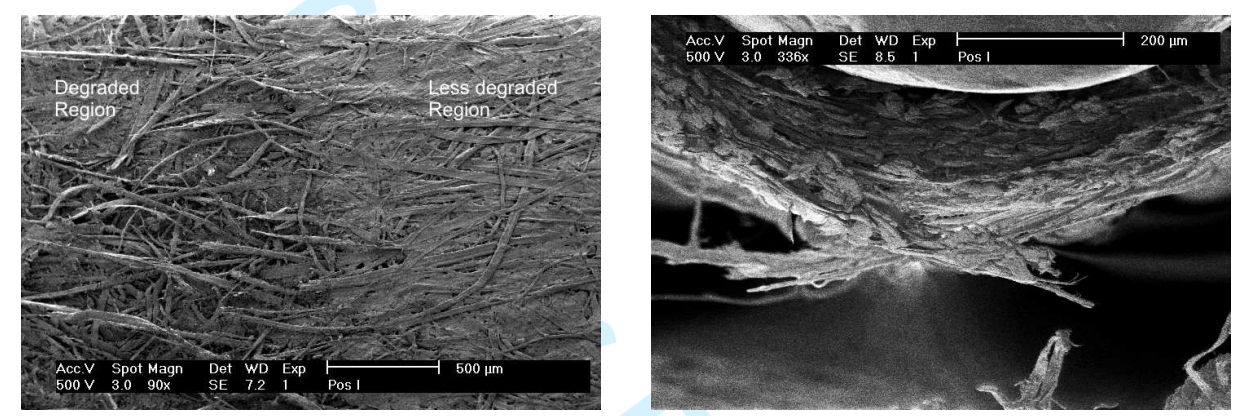

Figure 11. Micrographs of damage in the top liner under the creaser after completion of the creasing experiment

\section{Conclusions}

Finite element simulations of the creasing process based on experimentally measured paper properties allow one to predict the overall response of corrugated paperboard during a creasing experiment. The response is governed by a number of buckling events occurring in the flute, which show up as peaks in the loaddisplacement curves.

The first peak in the predicted load-displacement response, which indicates buckling of the flute, matches well with the experimental observation. Beyond the first peak, the shape of the predicted curve is somewhat different from the experimental observation, even though it follows the experimental band with reasonable accuracy.

The simulations correctly indicate locations in which damage and cracking are likely to occur. For the valley position this is primarily below the creaser, where damage - but no cracking - was observed in the experiments.

Predicting when and how the degradation progresses and finally leads to complete failure is beyond the capabilities of the present constitutive modelling, which indeed assumes undamaged properties throughout the thickness of the liner. To take the relevant damage and fracture mechanisms into account, a failure model needs to be incorporated in the material modelling, which is a topic of further research. 


\section{References}

[1] Q.S. Xia, M.C. Boyce, and D.M. Parks, A constitutive model for the anisotropic elastic-plastic deformation of paper and paperboard, International Journal of Solids and Structures 39 (2002), pp. 4053-4071.

[2] N. Stenberg, A model for the through-thickness elastic-plastic behavior of paper, International Journal of Solids and Structures 40 (2003), pp. 7483-7498.

[3] J. Castro and M. Ostoja-Starzewski, Elasto-plasticity of paper, International Journal of Plasticity 19 (2003), pp. 2083-2098.

[4] P. Makela and S. Ostlund, Orthotropic elastic-plastic material model for paper materials, International Journal of Solids and Structures 40 (2003), pp. 5599-5620.

[5] P. Isaksson, R. Hagglund, and P. Gradin, Continuum damage mechanics applied to paper, International Journal of Solids and Structures 41 (2004), pp. 4731-4755.

[6] P. Isaksson and R. Hagglund, A mechanical model of damage and delamination in corrugated board during folding, Engineering Fracture Mechanics 72 (2005), pp. 2299-2315.

[7] R.H.J. Peerlings et al., Gradient enhanced damage for quasi-brittle materials, International Journal for Numerical Methods in Engineering 39 (1996), pp. 3391-3403.

[8] P. Isaksson, P.A. Gradin, and A. Kulachenko, The onset and progression of damage in isotropic paper sheets, International Journal of Solids and Structures 43 (2006), pp. 713-726.

[9] T. Nordstrand, Analysis and testing of corrugated board panels into the post-buckling regime, Composite Structures 63 (2004), pp. 183-199.

[10] M.E. Biancolini, Evaluation of equivalent stiffness properties of corrugated board, Composite Structures 69 (2005), pp. 322-328.

[11] T.J. Urbanik, Machine direction strength theory of corrugated fiberboard, Journal of Composites Technology and Research 18 (1996), pp. 80-88.

[12] A.C. Gilchrist, J.C. Suhling, and T.J. Urbanik, Nonlinear finite element modeling of corrugated board, Mechanics of Cellulosic Materials ASME 85 (1999).

[13] U. Nyman, Continuum mechanics modeling of corrugated board, PhD Thesis, Lund University, Lund, Sweden, 2004.

[14] C. Barbier, P.L. Larsson, and S. Ostlund, Numerical investigation of folding of coated papers, Composite Structures 67 (2005), pp. 383-394.

[15] C. Barbier, P.L. Larsson, and S. Ostlund, On dynamic effects at folding of coated papers, Composite Structures 67 (2005), pp. 395-402.

[16] M. Murayama et al., Orthotropic effect and strain dependency of paperboard on load characteristic of center bevel cutter indented on paperboard, Journal of Materials Processing Technology 159 (2005), pp. 199-205.

[17] T. Nordstrand and L.A. Carlsson, Evaluation of transverse shear stiffness of structural core sandwich plates, Composite Structures 38 (1997), pp. 145-153.

[18] S.I. Cavlin and B. Edholm, Converting cracks in corrugated board. Effect of liner and fluting properties, Packaging Technology and Science 1 (1988), pp. 25-34.

[19] M.J. Pindera and C.T. Herakovich, Shear characterization of unidirectional composites with the offaxis tension test, Experimental Mechanics 26 (1986), pp. 103-112. 


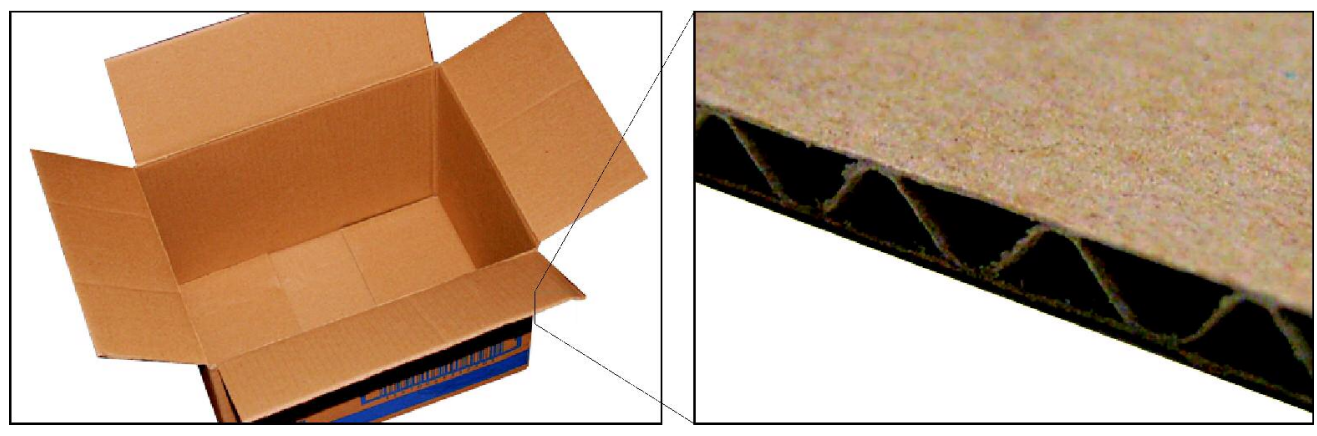

Figure 1

$275 \times 87 \mathrm{~mm}(600 \times 600 \mathrm{DPI})$ 


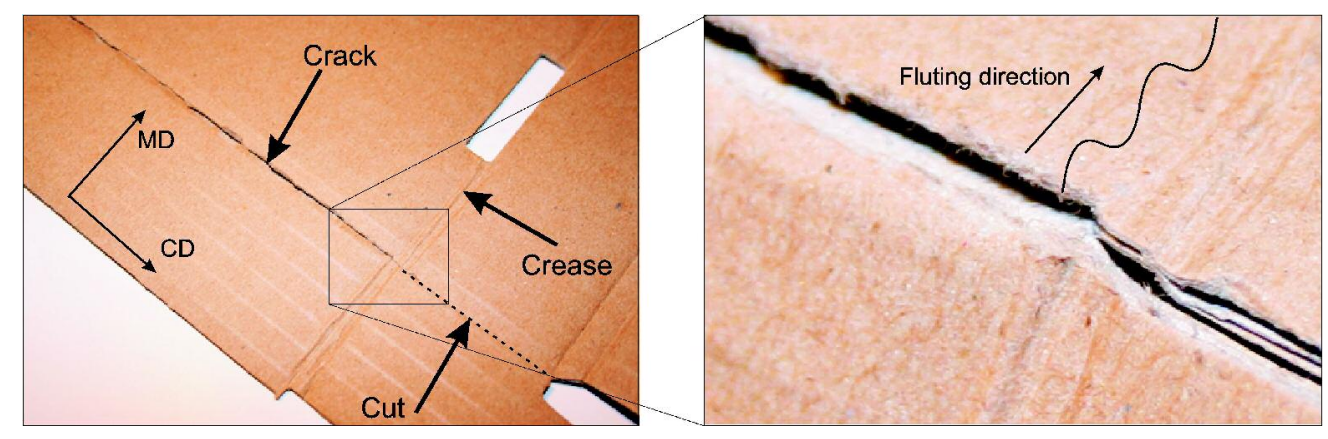

Figure 2

$226 \times 71 \mathrm{~mm}(600 \times 600 \mathrm{DPI})$ 


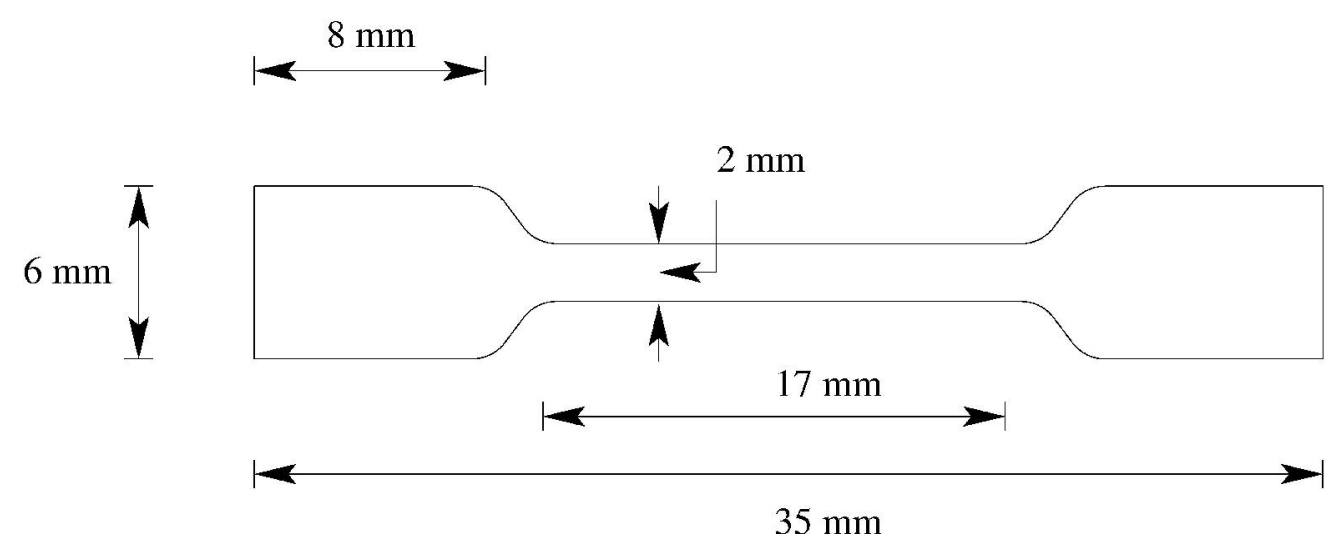

Figure 3

$214 \times 89 \mathrm{~mm}(600 \times 600 \mathrm{DPI})$ 


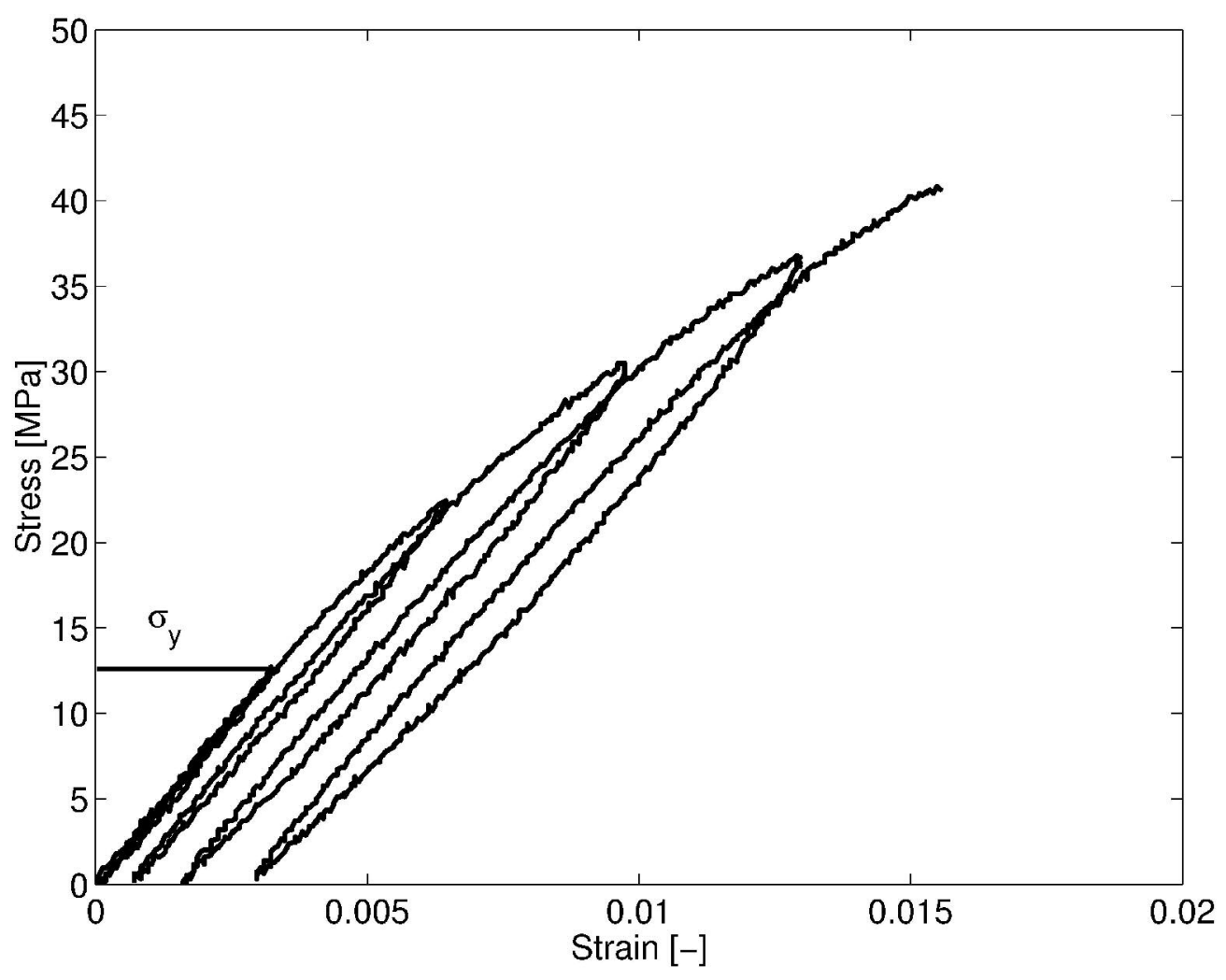

Figure 4

$176 \times 140 \mathrm{~mm}(600 \times 600$ DPI $)$ 


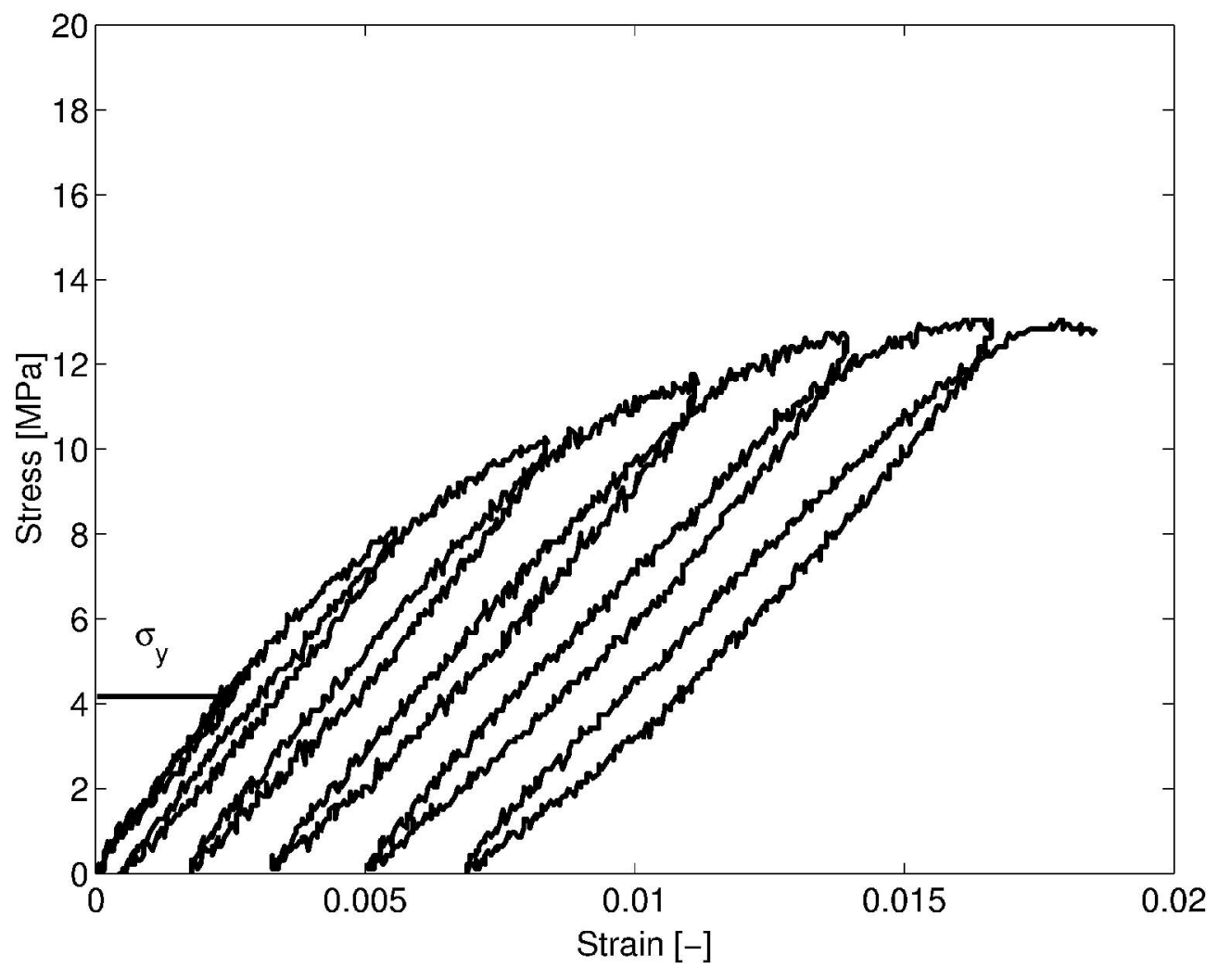

Figure 4

$176 \times 141 \mathrm{~mm}(600 \times 600$ DPI $)$ 


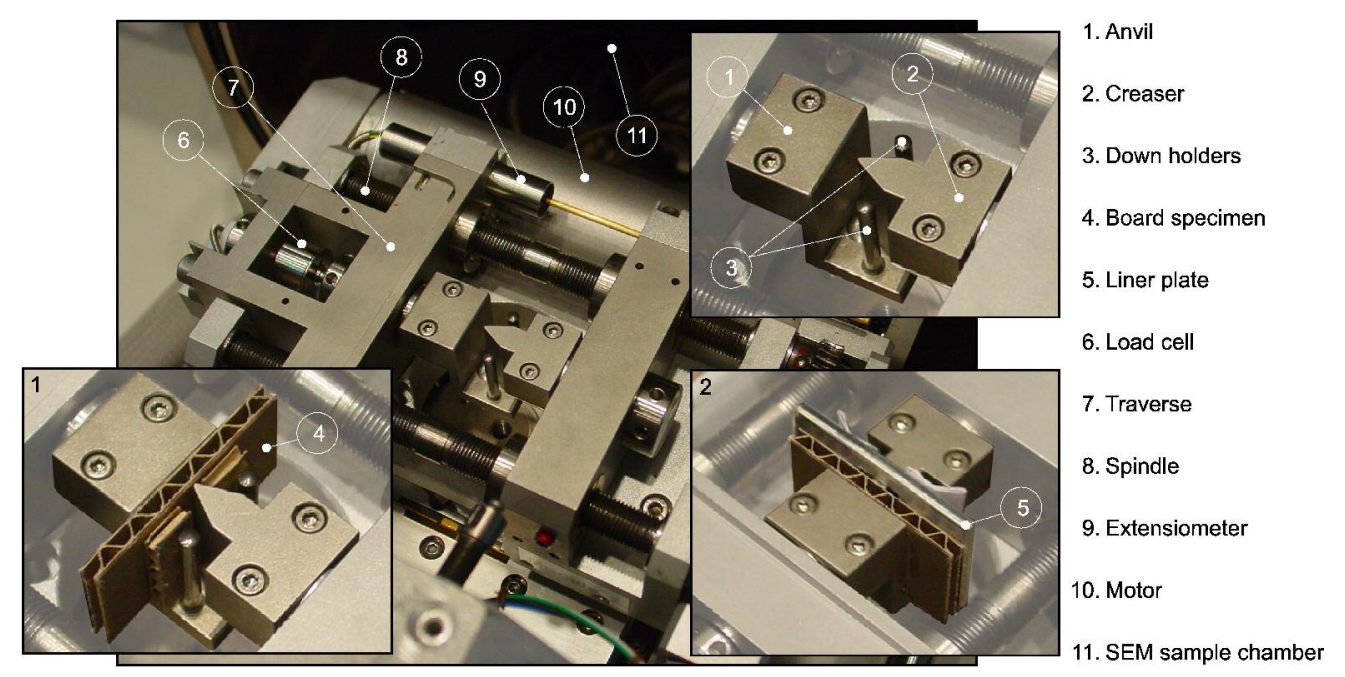

Figure 5

$206 \times 102 \mathrm{~mm}(600 \times 600 \mathrm{DPI})$ 


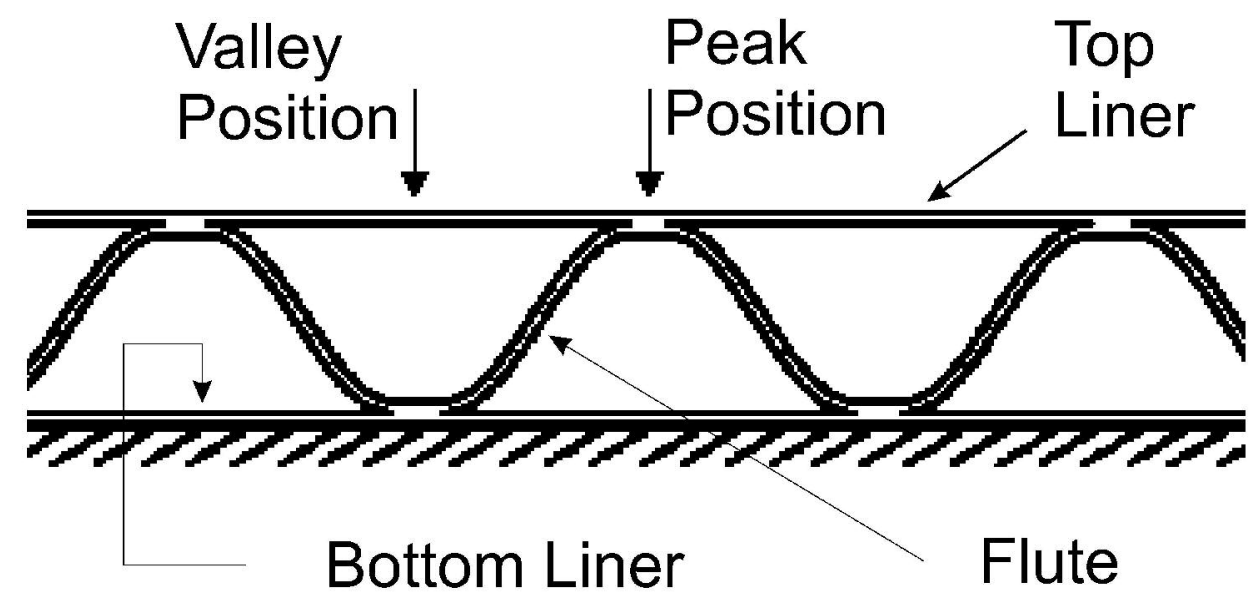

Figure 6

$144 \times 70 \mathrm{~mm}(600 \times 600 \mathrm{DPI})$ 


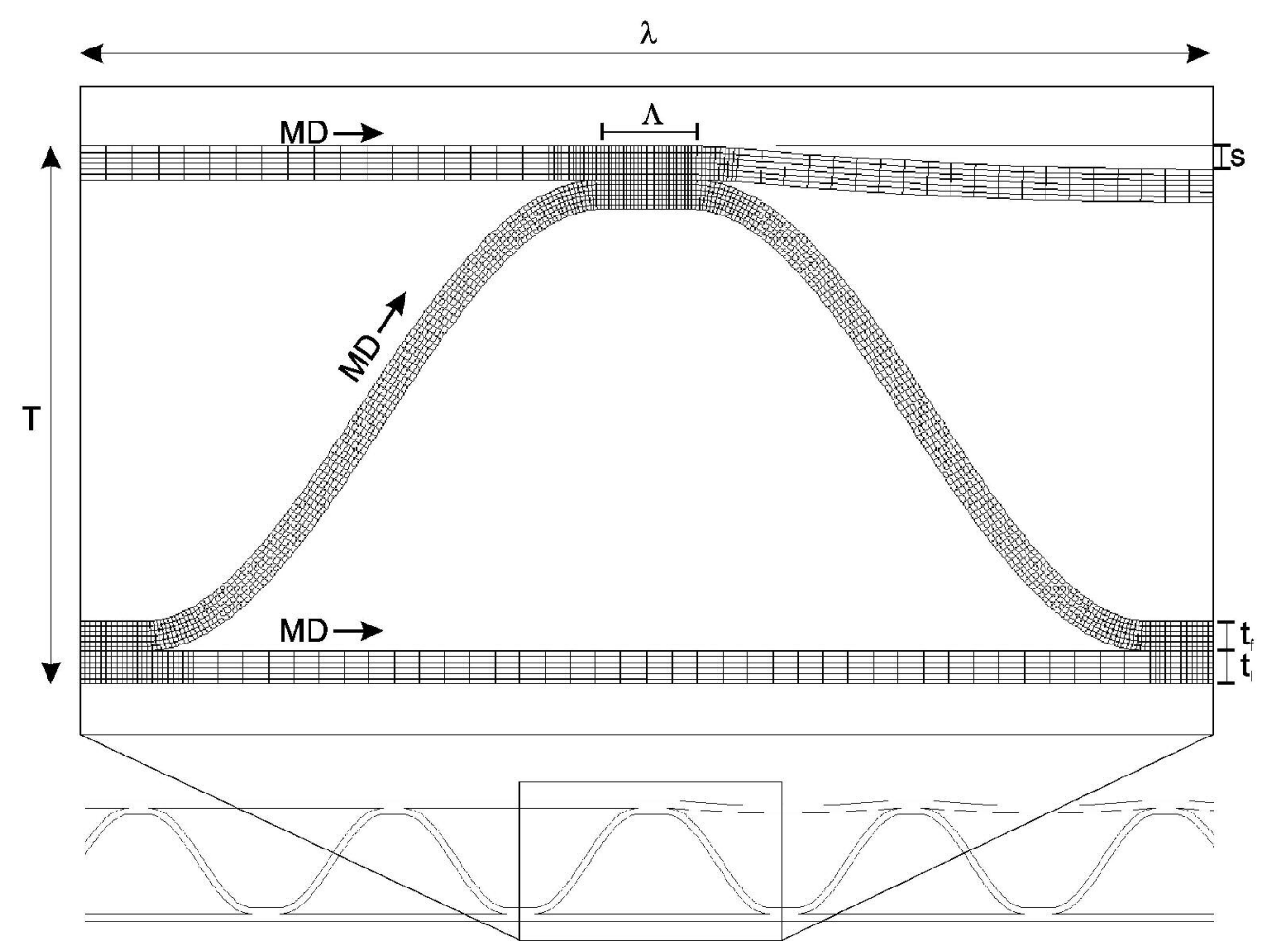

Figure 7

$136 \times 101 \mathrm{~mm}(600 \times 600 \mathrm{DPI})$ 


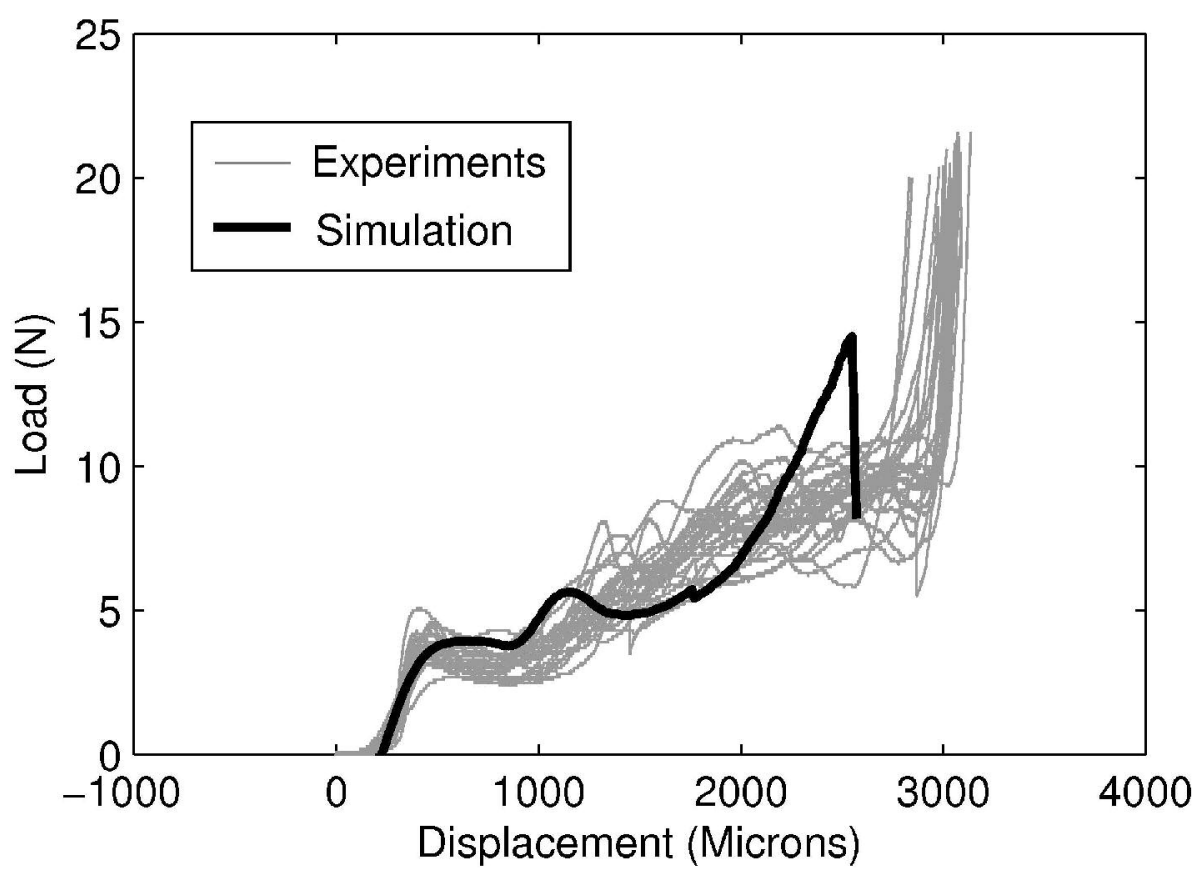

Figure 8

$108 \times 75 \mathrm{~mm}(600 \times 600 \mathrm{DPI})$ 


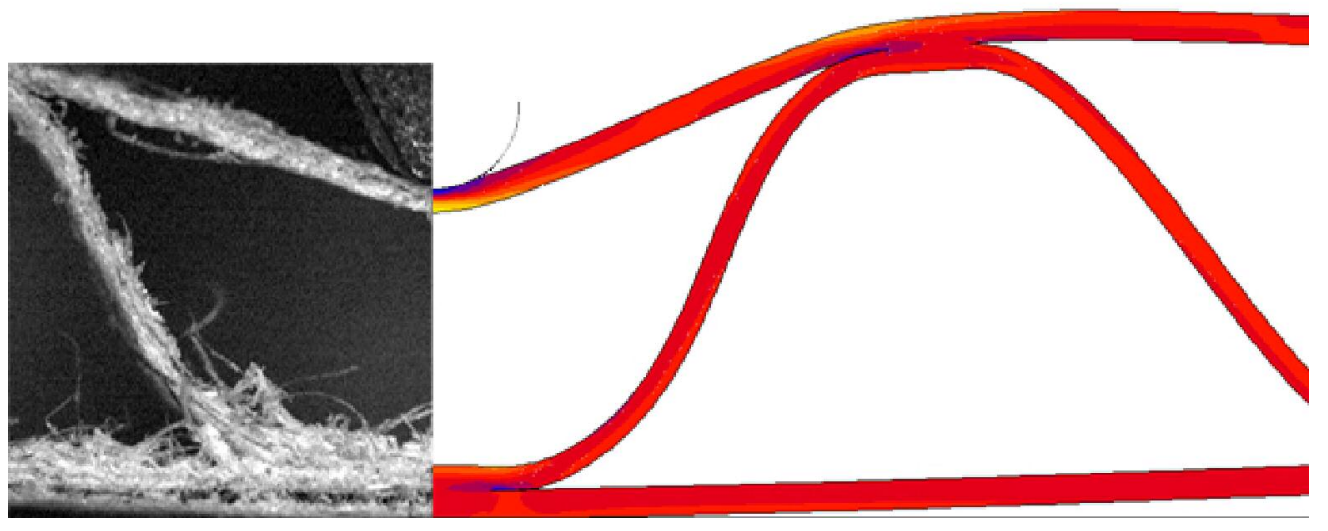

Figure 9

$211 \times 88 \mathrm{~mm}(600 \times 600$ DPI $)$ 


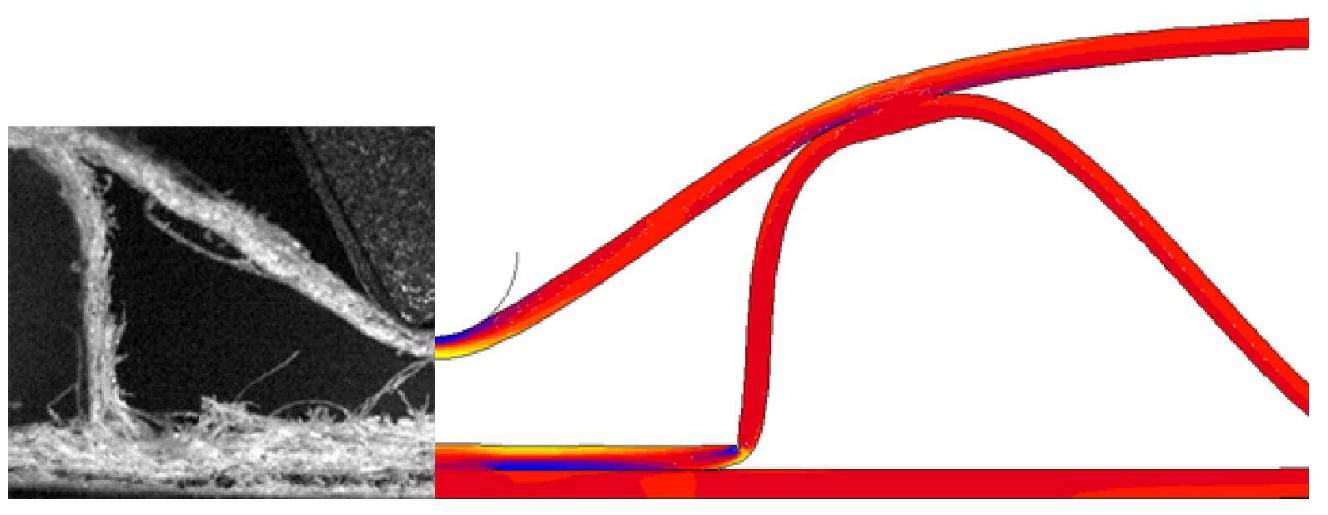

Figure 9

$211 \times 88 \mathrm{~mm}(600 \times 600$ DPI $)$ 


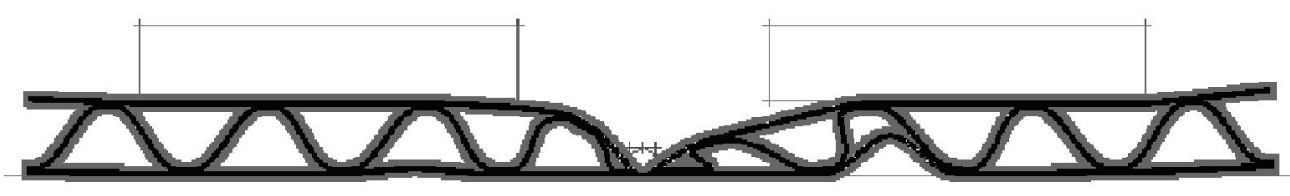

Figure 10

$348 \times 61 \mathrm{~mm}(600 \times 600 \mathrm{DPI})$ 


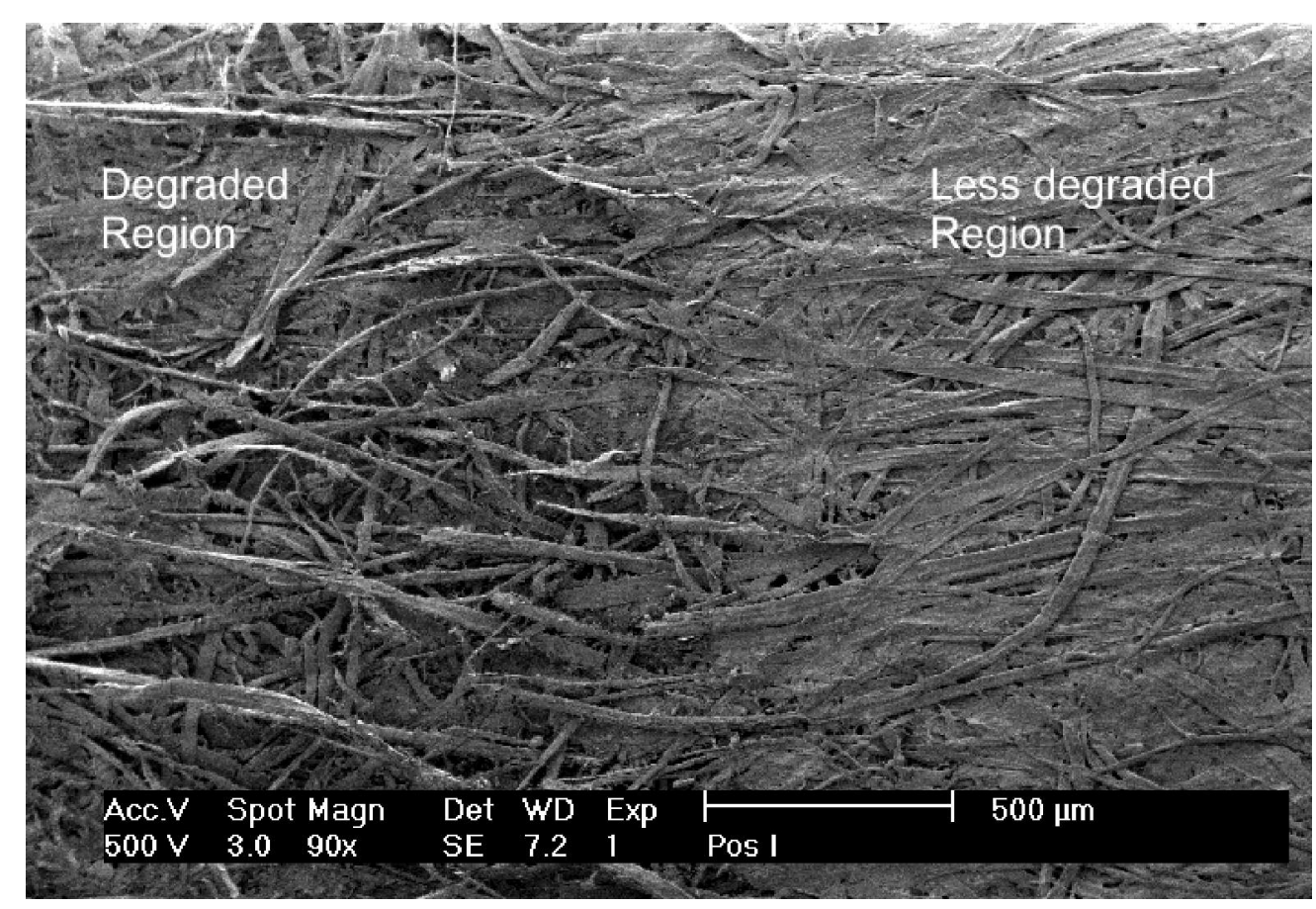

Figure 11

$251 \times 170 \mathrm{~mm}(600 \times 600 \mathrm{DPI})$ 


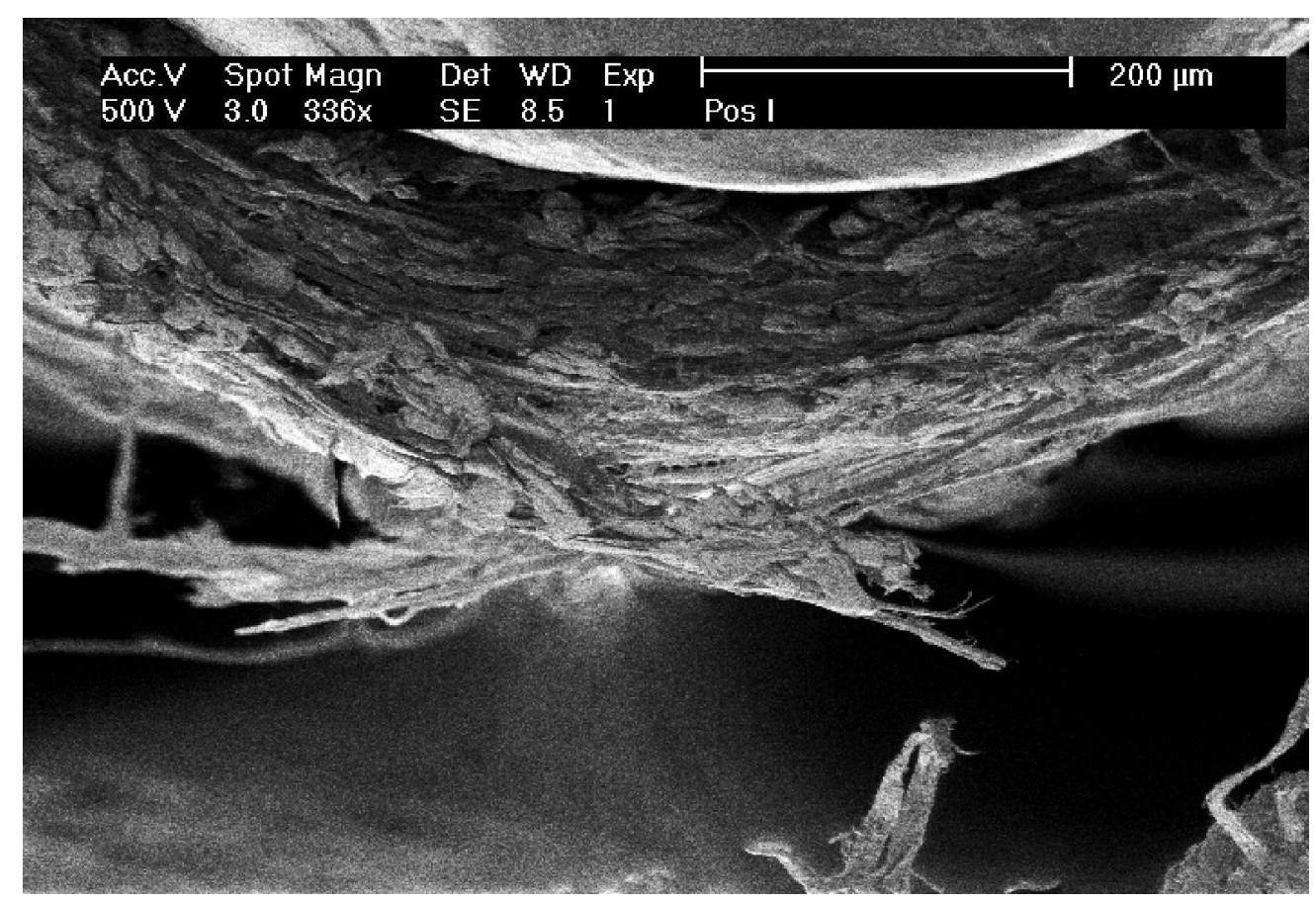

Figure 11

$251 \times 170 \mathrm{~mm}(600 \times 600 \mathrm{DPI})$ 